\title{
UTILIZAÇÃO DE VERMICULITA GOMO MINERAL-TESTE NO MONITORAMENTO DA DINÂMICA ATUAL DE COBERTURAS PEDOLÓGICAS
}

\author{
GERAIDO C. ROCHA* \& CARLOS C. CERRI**
}

\begin{abstract}
UTILIZATION OF VERMICULITE AS TEST MINERAL IN MONITORING THE ACTUAL DYNAMICS OF PEDOLOGICAL COVERS. The geochemical dynamics of soil mantles developed over basic rocks in the north and south regions of Brazil were monitored, using the experimental methods oftest mineral (vermiculite) and exchange sintetic resins. These "chemical traps" were introduced into the soils and after one year of permanence (corresponding to the dry and wet seasons) they were sampled. Chemical characterization and X-ray diffractometry showed that in the pedological cover of the Amazonic region are acting pedological mechanisms of podzolization, definingachemicallyacid-complexingmediun. The soils of the south region are suffering acidification, denotingadeep weathered environment.
\end{abstract}

Keywords: Experimental pedology, test-minerals, geochemical monitoring, vermiculite.

\begin{abstract}
RESUMO O objetivo deste trabalho foi mostrar os resultados experimentais obtidos com a útil ização de mineral teste (vermiculitamacroscópica) e resinasintéticatrocadora de íons, empregados parao monitoramento da dinâmica geoquímica atual de coberturas pedológicas desenvolvidas sobre rochas básicas nas regiões Norte e Sul do Brasil. Essas "armadilhas" foram introduzidas nos solos e amostradas após período de um ano (correspondente às épocas seca e chuvosa acumuladas). Caracterizações químicas e difratometria de raios X possibilitaram concluir que na cobertura pedológica da região amazônica estão atuando mecanismos pedológicos de podzolização, definindo um ambiente geoquímico ácido-complexante. Os solos da Região Sul (Paraná) estão sofrendoacidificacão, denotando um ambiente mais agressivo $\mathrm{l} l$ ixivian te.
\end{abstract}

Palavras-chaves: Pedologia experimental, minerais-teste, monitoramento geoquímico, vermiculita.

INTRODUÇÃO O conhecimento das características e da dinâmica de coberturas superficiais é resultante da interpretação de análises de amostras de solos. O teor em argila, a mineralogia ou as características químicas, definem não um ambiente pedoquímico atual, mas a somatória de vários processos pelos quais passou o solo ao longo do tempo, (Ranger \& Robert 1985). Esses dados, apesar de revelarem um mecanismo pedológico dominante, refletem, na verdade, toda a história acumulada da gênese e evolução do solo considerado.

É de extrema importância o conhecimento e monitoramento dos processos atuais que ocorrem nas coberturas pedológicas, sejam eles ao longo de um ano, ou mesmo durante uma estação seca ou úmida, pois já se sabe que vários processos que atuam na evolução de alguns tipos de solos são sazonais (Felix 1987).

Nos últimos anos tem sido utilizado, principalmente na França, o chamado método experimental dos minerais-teste (Hatton et al. 1987, Berthelin et al. 1983), para se acompanhar a dinâmica geoquímica de coberturas pedológicas; esse método, aliado à utilização de resinas sintéticas trocadoras de ions, (Binkley \& Matson 1983), tem se mostrado eficientes para esse fim, sendo potencialmente úteis para aplicação em estudos de poluição de solos, dinâmica iônica e iniemperismo experimental (Rocha 1990).

Foi usada essa metodologia experimental em coberturas pedológicas do Brasil, sendo o objetivo deste trabalho mostrar os resultados obtidos em duas áreas, uma localizada na Amazônia (Estado do Pará, Município de Prainha, Estação Experimental da CEPLAC, km 100 da Rodovia Transamazônica) e outra no sul do país (Londrina, Paraná, campus da Universidade Estadual de Londrina). A área de estudo localizada na região norte está sob clima tropical úmido, com temperatura média anual de $26^{\circ} \mathrm{C}$ e pluviosidade média anual de $1.680 \mathrm{~mm}$; o relevo é de planalto e a vegetação é uma floresta equatorial. O local de estudo da região sul está em clima subtropical úmido, com temperatura e pluviosidade médias anuais de respectivamente $22,5^{\circ} \mathrm{C}$ e $1.615 \mathrm{~mm}$; o relevo também é de planalto e a vegetação de floresta tropical.

METODOLOGIA $\mathrm{Na}$ figura 1 estão indicados os locais selecionados para este trabalho. Em ambas as regiões, as coberturas pedológicas desenvolveram-se sobre rochas básicas de idade e petrografia semelhantes; ao norte do país temse o diabásio Penatecaua (Departamento Nacional da Produção Mineral 1974), introduzido nos sedimentos da Bacia do Amazonas durante o intervalo Jurássico-Cretáceo. Ao sul, a rocha é um basalto da Formação Serra Geral (Departamento Nacional da Produção Mineral 1978), que faz parte da Bacia do Paraná. A mineralogia dessas rochas constitui-se basicamente de labradorita e augita, tendo como acessórios magnetita, apatita e opacos.

Em cada uma dessas áreas, selecionaram-se vertentes características, onde foram locadas e perfuradas trincheiras pedológicas para os segmentos de relevo de topo e meia encosta. A morfologia das coberturas pedológicas foi estudada conforme os critérios propostos por Lemos \& Santos (1984), separando-se os horizontes dos solos para cada perfil da seqüência.

Para a instalação dos minerais-teste e das resinas trocadoras de íons, escolheu-se, ao longo das vertentes das duas áreas, horizontes representativos dos mecanismos pedogenéticos e classificação de solos. Foram utilizados o horizonte B latossólico (em posição de topo de relevo), o horizonte B textural (na encosta) e o horizonte A 1 , o qual se estende ao longo da porção superficial de toda a vertente. A figura 2 mostra a disposição espacial desses horizontes na paisagem.

Método do mineral-teste Para a preparação da vermi-

\footnotetext{
* Laboratório de Geologiae Pedologia, Departamento de Geociências, Universidade Estadual de Londrina, CEP 86055-900, Londrina, PR, Brasil

** Seção de Química do Solo, Centro de Energia Nuclear na Agricultura. Avenida Centenário s/nº Caixa Postal 96, CEP 13400-970, Piracicaba, SP, Brasil
} 


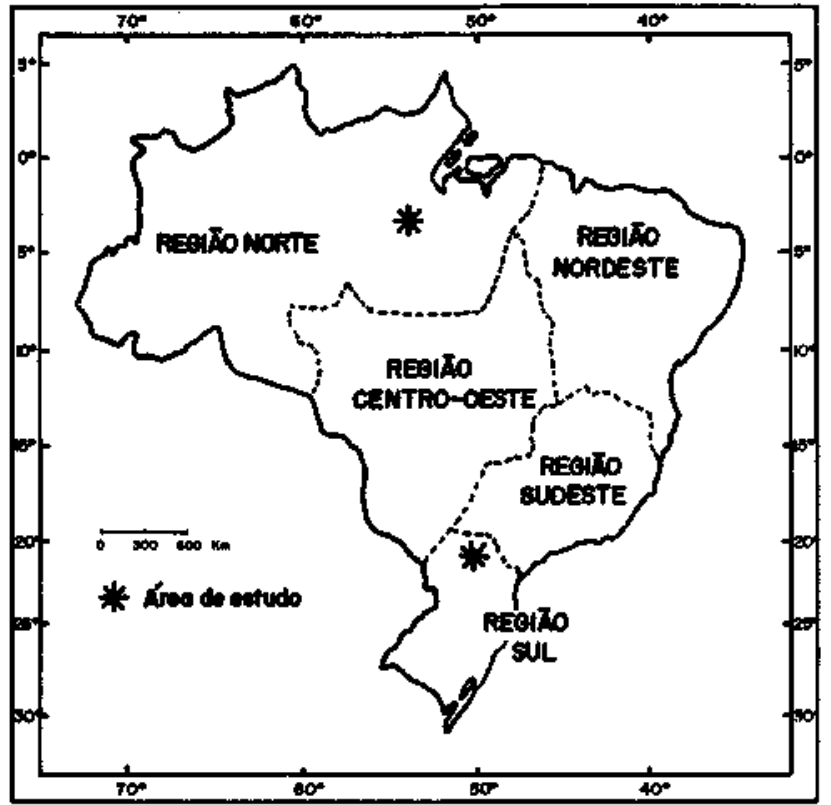

Figura 1 - Localização das áreas de estudo no Brasil Figure l - Location of the studied areas in Brazil

culita, utilizaram-se cristais de diâmetro de dois a três centímetros desse mineral, obtido na região de Catalão, Goiás, o qual foi moído e peneirado até se obter material no diâmetro compreendido entre 0,149 e $0,250 \mathrm{~mm}$. Foram pesadas $5 \mathrm{~g}$ e acondicionadas em saquinho de nylon (Mono-Ti, UGB, Panissieres, França) com dimensões de 7 x $3 \mathrm{~cm}$ e malha de 33 um. Cada saquinho, devidamente lacrado, foi inserido em galeria de aproximadamente $5 \mathrm{~cm}$ de diâmetro por $100 \mathrm{~cm}$ de profundidade, perfurada nas paredes das trincheiras abertas para o estudo dos solos. Uma etiqueta de placa de alumínio numerada foi amarrada ao saquinho por fio de nylon, ficando desse modo de fora da galeria (Fig. 3). As galerias foram perfuradas seguindo-se a morfologia dos perfis, ou seja, para cada horizonte pedológico foram colocados dois saquinhos com vermiculita, fechando-se em seguida as galerias para se tentar manter as condições naturais do solo.

Na Região Sul do Brasil, essas "armadilhas" foram colocadas em fevereiro de 1987 e amostradas em março de 1988 (correspondendo às épocas seca e chuvosa acumuladas).

Para a Região Amazônica, as amostras foram inseridas em julho de 1987 e retiradas dos solos em maio de 1988 (também correspondendo às duas estações). A amostra de vermiculitatestemunho (mineral original) e as amostras que permaneceram no solo foram submetidas às seguintes caracterizações analíticas:

1. pH em água: agitação de $0,2 \mathrm{~g}$ de vermiculita em $5 \mathrm{ml}$ de

água destilada. Leitura em potenciômetro após agitação. 2. $\mathrm{Ca}^{2+}, \mathrm{Mg}^{2 *}, \mathrm{Na}^{+}$e $\mathrm{K}^{+}$: extração com $\mathrm{HC} 10,05 \mathrm{~N}$ e fazendose leitura em espectrofotômetro de absorção atômica. 3. $H^{*^{+}}$e $A P^{+}$: extração com $\mathrm{KC} 1 \mathrm{~N}$ para $\mathrm{H}+\mathrm{Al}$ e titulação com $\mathrm{NaOH} 0,025 \mathrm{~N}$ e fenolftaleína 1\%; titulação com HC1 0,025 $\mathrm{N}$ para AP, determinando-se $\mathrm{H}+$ por diferença.

4. Capacidade de troca de cations (CTC): soma dos cations trocáveis e $\mathrm{H}+\mathrm{A} 1$.

5. Ferro, alumínio e silício', analisados para o testemunho, pelo método do citrato-bicarbonato-ditionito (Mehra e Jackson 1960).

6. Difratometria de raios $X$ : para amostras saturadas com potássio, magnésio, glicoladas e aquecidas.

Método da resina trocadora de íons Para o monitoramento da dinâmica atual dos solos, foi adaptada a técnica das resinas trocadoras de íons utilizada por Binkley \& Matson (1983) e Binkley \& Hart (1985). Trabalhou-se com a resina Dowex SOW X8, catiônica, com diâmetro de 29 a 50 mesh e CTC (a seco) de 5,1 meq/g, preparada do seguinte modo: lavagem com água destilada e soda $4 \mathrm{~N}$; secagem ao ar, ficando saturada com íons $\mathrm{Na}^{*}$. Foram pesados $15 \mathrm{~g}$ desse material, o qual foi colocado em saquinho de nylon e inserido no solo, da mesma forma que o mineral teste.

As resinas foram inseridas nos solos e amostradas nas mesmas épocas dos minerais-teste.

A metodologia analítica de extração e dosagem foi a seguinte: 1. $\mathrm{Ca}^{2+}, M g^{2+}$ e $1 C$ : extração com $\mathrm{HCl} 0,05 \mathrm{~N}$ e agitação por 15 minutos, com leitura em espectrofotômetro de absorção atômica.

2. $H^{+}$e $A P^{+}$: extração com $\mathrm{KC1N}$ para $\mathrm{H}+\mathrm{A} 1$ e titulação com $\mathrm{NaOH} 0,025 \mathrm{~N}$ e HC10,025 N para $\mathrm{Al}^{3+}$, determinando-se $\mathrm{H}^{+}$ por diferença.

RESULTADOS E DISCUSSÃO REGIÃO NORTE Transformações estruturais do mineral teste As evidências de transformações mineralógicas ocorridas no mineral-teste após sua permanência no solo, assim como a caracterização estrutural do mineral testemunho podem ser visualizadas na figura 4.

O mineral inicial (testemunho) se caracteriza, na saturação com potássio, por um espaçamento predominante de 1,4 nm entre as lâminas, sendo que algumas se fecham a 1,2 nm. A glicolação com magnésio expande uniformemente o espaçamento a $1,5 \mathrm{~nm}$; os aquecimentos empregados mantêm os picos unificados a $1,1 \mathrm{~nm}$.

No horizonte Bw (latossólico), o mineral-teste amostrado e saturado com potássio a $25^{\circ} \mathrm{C}$ não mostrou variação significativa em relação ao testemunho, mantendo picos a 1,4 e 1,2 $\mathrm{nm}$. Na saturação com magnésio e na glicolação ocorre pequena modificação na posição dos picos com relação ao testemunho, indo a $1,47 \mathrm{~nm}$ com magnésio e a 1,38 com glicolação. A variação marcante foi verificada nos aquecimentos, onde, a $350^{\circ} \mathrm{C}$, a maior parte das lâminas do mineral se fecha a $1,2 \mathrm{~nm}$, com algumas permanecendo a $1,4 \mathrm{~nm}$. A $550^{\circ} \mathrm{C}$, apesar de se manter o pico $1,1 \mathrm{~nm}$, é verificada a permanência do componente a $1,4 \mathrm{~nm}$.

Para os horizontes Al e Bt da cobertura pedológica da região Norte, para o tratamento com potássio a $25^{\circ} \mathrm{C}$, não existe variação em relação ao testemunho; na saturação com magnésio, somente no A 1 é verificado deslocamento do pico a $1,38 \mathrm{~nm}$, em relação à posição de $1,52 \mathrm{~nm}$ do testemunho. No tratamento com magnésio e glicolação, o horizonte Bt imprime modificação na posição do pico, o qual se desloca para $1,57 \mathrm{~nm}$.

Os aquecimentos mostram as variações mais significativas para o horizonte superficial (Al) e para o B textural. Para o A l, é observado que, a $350^{\circ} \mathrm{C}$, coexistem dois espaçamentos: 1,44 e $1,24 \mathrm{~nm}$; e mesmo a $550^{\circ} \mathrm{C}$, mantém-se o pico a 1,42 $\mathrm{nm}$, apesar do fechamento de grande parte das lâminas a 1, 13 $\mathrm{nm}$. Comportamento praticamente semelhante é observado nos aquecimentos para o horizonte $\mathrm{Bt}$ : $\mathrm{a} 350^{\circ} \mathrm{C}$, são vistos dois picos $(1,42 \mathrm{e} 1,16 \mathrm{~nm})$; a $550^{\circ} \mathrm{C}$, predomina o espaçamento de $1,1 \mathrm{~nm}$ entre as lâminas, apesar de permanecer também um pico a $1,47 \mathrm{~nm}$ nesse tratamento.

COMPORTAMENTO QUÍMICO DO MINERAL-TESTE $\mathrm{Na}$ tabela 1, estão os resultados químicos obtidos para os minerais teste instalados na cobertura pedológica da região amazônica em comparação ao mineral-testemunho; a tabela 2 apresenta a caracterização química das resinas trocadoras de íons.

E possível observar inicialmente na tabela 1, que o mineral testemunho apresenta Capacidade de Troca de Cations (CTC) de aproximadamente $47 \mathrm{eqmg} / 100 \mathrm{~g}$ de material. Os sítios de troca estão preenchidos predominantemente por magnésio trocável; o íon cálcio vem em segundo lugar, com aproxima- 

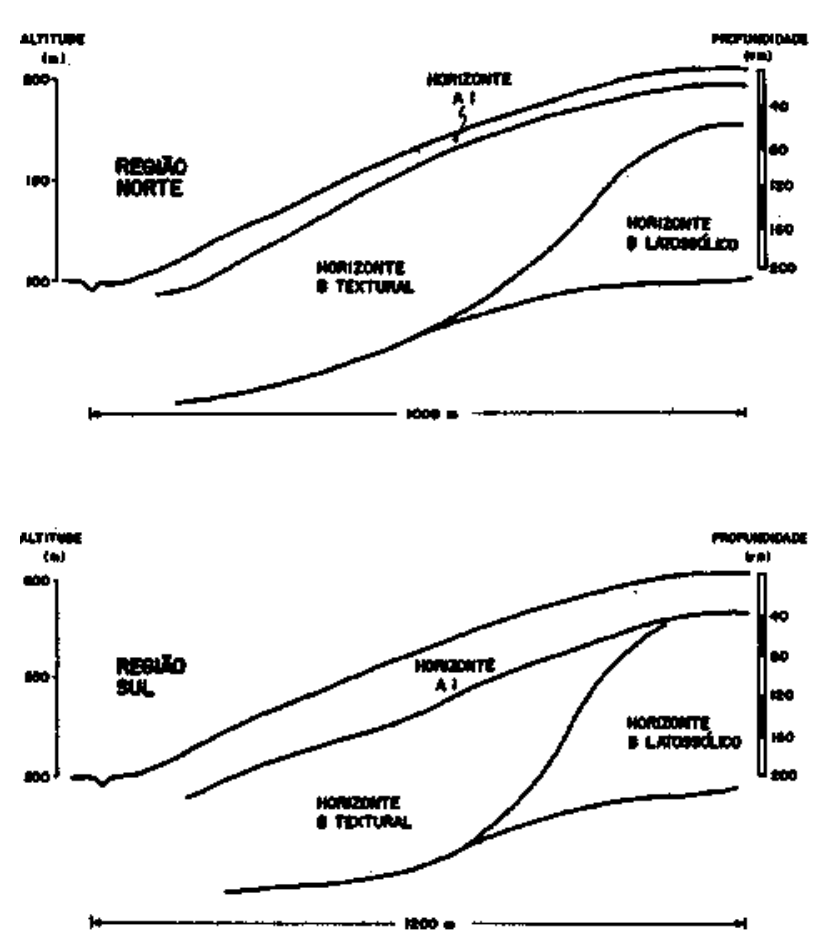

Figura 2 - Disposição espacial dos horizontes pedológicos Figure 2 - Spatial distribution of the pedological horizons

damente 2 eqmg/100 g; sódio, potássio, hidrogênio e alumíniotrocáveis, juntos, perfazem apenas 1 eqmg/100 g material. Após um ano de instalação no solo, o mineral-teste mostra diminuição significativa da CTC e de magnésio adsorvido aos sítios de troca do mineral, de maneira semelhante para toda a cobertura pedológica.

Pode-se pensar que houve aumento relativo do cálcio para todos os horizontes considerados. O cálcio ocupa 2 eqmg do total de 47 eqmg de CTC do mineral testemunho, o que representa $4,5 \%$ do total.

A CTC do mineral-teste decresce para 10 eqmg, enquanto o cálcio permanece com 2 eqmg, caracterizando um aumento relativo de $20 \%$, em relação aos sítios de troca disponíveis para ocupação iônica. O magnésio, apesar da redução em relação ao mineral-testemunho, mantém-se como o cátion predominante no complexo de troca, ocupando aproximadamente $70 \%$ dos sítios disponíveisno mineral-teste. Asresinas catiônicas confirmam que cálcio e magnésio são os elementos mais retidos, indicando uma solução do solo rica nesses elementos.

DINÂMICA PEDOLÓGICA DA REGIÃO NORTE A utilização dos métodos do mineral-teste e da resina trocadora de íons mostrou as tendências gerais do funcionamento atual do sistema pedológico da Região Norte.

O mineral utilizado é uma vermiculita macroscópica hidroxialuminosa (Barnhisel 1982). A amostra testemunho, além de não se fechar a $1,0 \mathrm{~nm}$ a $550^{\circ} \mathrm{C}$, apresentou teor de alumínio extraído pelo método CBD relativamente elevado. Segundo Hatton et al. (1987), trata-se de um mineral com bloqueio interfoliar hidroxialuminoso. Esse bloqueio se reflete nas características químicas do mineral testemunho, cuja CTC comparativamente baixa deve ser considerada como relativa para esse fílossilicato, já que outras amostras de vermiculita descritas na literatura apresentam CTC bem mais elevada (Felix 1987).

Além disso, o pico a 1,2 nm na amostra testemunho saturada com $\mathrm{K}^{+}$a $25^{\circ} \mathrm{C}$ deve tratar-se de camada interestratificada tipo mica-clorita, a qual também vai influir no comportamento estrutural desse mineral quando introduzido no solo.

Os resultados químicos obtidos com as resinas iônicas caracterizam a solução do solo (Binkley \& Hart 1985), a qual para o sistema pedológico considerado revelou alta mobilização de cálcio e magnésio (Tab. 2), principalmente no volume pedológico superficial (horizonte A), sugerindo um ambiente geoquímico alcalino a neutro.

As modificações estruturais do mineral-teste instalado e amostrado após um ano no solo foram relativamente semelhantes para todos os volumes pedológicos monitorados na região amazônica.

Essas modificações se tornaram mais evidentes nas amostras aquecidas a $350^{\circ} \mathrm{C}$ e $550^{\circ} \mathrm{C}$, revelando, de maneira geral, "cloritização" dos minerais, com aparecimento de picos a 1,4 $\mathrm{nm}$, que correspondem ao da clorita (Besoain 1985).

Esse processo pode ser explicado levando-se em conta a riqueza do meio em magnésio, íon que teria penetrado entre as lâminas de vermiculita estabilizando-as como uma camada brucítica, a qual não foi extraída mesmo a temperaturas elevadas.

$\mathrm{O}$ bloqueio da vermiculita pelo alumínio, aliado à estabilização desse mineral pelas pontes de magnésio da camada brucítica (Barnhisel 1982), são fatores que podem explicar a drástica redução da CTC do mineral-teste instalado no sistema da região Norte.

A tabela 1 mostra que o complexo sortivo do mineral-teste foi preenchido predominantemente pelos íons cálcio e magnésio, fato que confirma o ambiente geoquímico definido pelos resultados obtidos com as resinas catiônicas.

AMBIENTE GEOQUÍMICO ATUAL DA COBERTURA PEDOLÓGICA A confrontação dos resultados químicos com a evolução mineralógica da vermiculita revelou-se coerente para o sistema da região amazônica; resta definir o mecanismo geoquímico que controlaria a dinâmica atual da organização mineralógica da região Norte.

As bases para interpretação dos resultados obtidos até agora com a utilização de minerais-teste (Ranger \& Robert 1985 , Hatton et al. 1987, Felix 1987) tem se apoiado no trabalho experimental de Robert et al. (1979): em um meio ácido e complexante (podzolização) a vermiculita seria submetida a um processo de desestabilização, com sua CTC progressivamente saturada com magnésio por acumulação relativa. Em um meio ácido não complexante o alumínio tenderia a se acumular entre as lâminas do mineral, formando vermiculita hidroxialuminosa.

Para o caso dessa pesquisa, entretanto, a vermiculita inicial (testemunho) já era aluminosa, o que torna mais complexa a interpretação, podendo inclusive mascarar a caracterização de um meio geoquímico ácido não complexante, caso esse ocorresse.

Contudo, a riqueza da solução do solo em magnésio e cálcio, aliada às características de saturação iônica do mineral-teste instalado e à desestabilização relativa da vermiculita, invalidam a hipótese de um meio não-complexante, parecendo mais coerente a idéia de se estar frente a um meio ácido com maior tendência à complexação do que a uma acidólise simples, mecanismos definidos por Robert et al. (1979).

Região Sul TRANSFORMAÇÕES ESTRUTURAIS $D O$ MINERAL-TESTE Na figura 5, tem-se os difratogramas obtidos para os minerais-teste instalados na Região Sul; por conveniência para comparação são repetidos os difratogramas do mineral inicial (testemunho).

Para o horizonte B latossólico, já se notam variações no tratamento com $\mathrm{K}^{+}$a $25^{\circ} \mathrm{C}$ em comparação ao testemunho, no qual os picos se encontram a 1,52 nm e 1,38 nm. Apesar de não se ter os tratamentos com $\mathrm{Mg}^{2+}$, os aquecimentos possibilitaram a visualização de outras modificações estruturais nos minerais instalados; a $350^{\circ} \mathrm{C}$, um pico a $1,49 \mathrm{~nm}$ se 


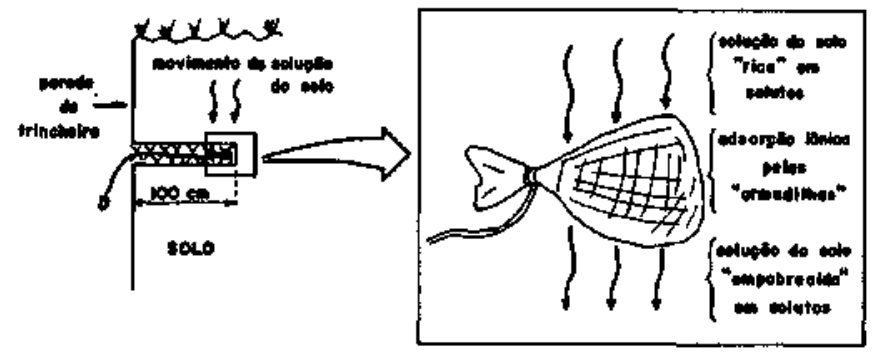

Figura 3-Esquema cie colocação das "armadilhas "geoquimicas Figure 3 - Instalation sketch ol'the gcochcmical "traps"

\section{VEAMICULITA TESTEMUNHTO}

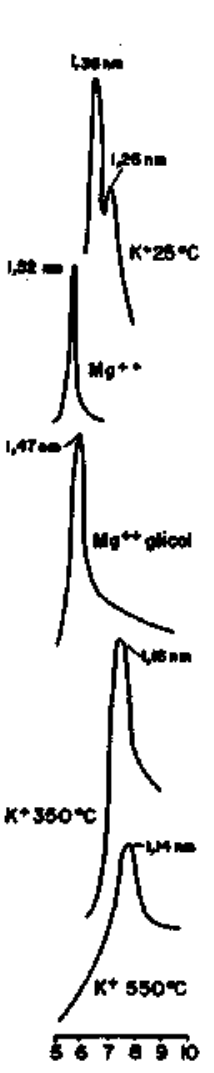

20
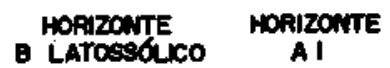

28

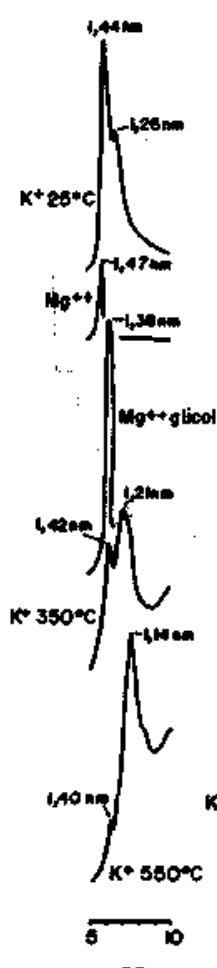

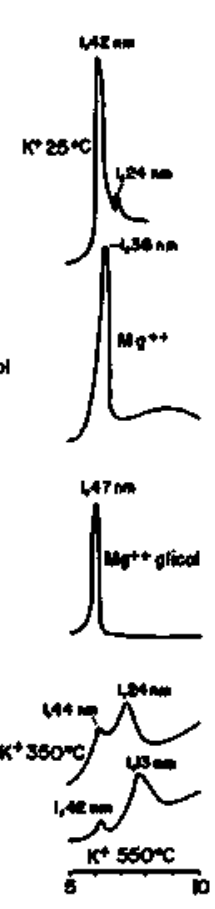

$\mathbf{2 0}$
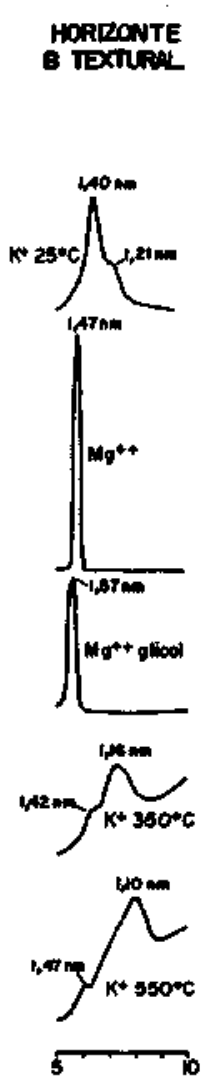

28
Figura 4 - Modificações estruturais do mineral-teste, após permanência de um ano na cobertura pedológica da região Norte

Figure 4 - Structural modifications of the test mineral after permanence of one year in the pedological cover of the North Region

manteve, sendo que o fechamento da maior parte das lâminas do mineral deu-se a $1,33 \mathrm{~nm}$. Mesmo a $550^{\circ} \mathrm{C}$, permaneceu um pequeno pico a $1,52 \mathrm{~nm}$, com a maior parte das lâminas fechando-se a $1,26 \mathrm{~nm}$.

O horizonte B textural não imprimiu variação no mineralteste tratado com $\mathrm{K}^{+}$a $25^{\circ} \mathrm{C}$ e $\mathrm{Mg}^{2+}$, em relação ao testemunho; mesmo na glicolação a variação de espaçamento de 1,47 nm (testemunho) para 1,44 nm nesse solo parece não ser significativa. Entretanto, os aquecimentos mostraram diferenças, na persistência de um pico a $1,4 \mathrm{~nm}$, acompanhando picos a 1,17 $\mathrm{nm}\left(\mathrm{a} 350^{\circ} \mathrm{C}\right)$ e a $1,09 \mathrm{~nm}\left(\mathrm{a} 550^{\circ} \mathrm{C}\right)$.

Para o horizonte superficial (A l) da região Sul, a saturação com $\mathrm{K}^{+}$a $25^{\circ} \mathrm{C}$ já mostrou deslocamento para picos a $1,47 \mathrm{~nm}$ e 1,28 nm. Na saturação com $\mathrm{Mg}^{2+}$, não se detectou variação,
Tabela 1 - Resultados químicos dos minerais-teste instalados na região Amazônica

Table 1 -Chemical results ofthe test minerals instated in the Amazonic region

\begin{tabular}{|c|c|c|c|c|c|c|c|c|c|c|c|}
\hline \multirow{2}{*}{$\begin{array}{l}\text { LCCAL } \\
\text { AMEOSTAAD }\end{array}$} & \multirow{2}{*}{ HOA } & \multirow{2}{*}{$\begin{array}{c}\text { PROF } \\
\text { inSTH } \\
\text { (amil) }\end{array}$} & \multirow{2}{*}{ pH } & \multicolumn{5}{|c|}{ 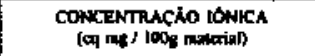 } & \multicolumn{3}{|c|}{ Extrypa CBD } \\
\hline & & & & $a^{b}$ & $\mathrm{MB}_{\mathrm{g}}^{\mathrm{In}}$ & $\mathrm{Ni}^{+}$ & $\mathbf{x}^{+}$ & $\mathbf{H}^{+}$ & Fe & $\boldsymbol{A}$ & s \\
\hline $\begin{array}{l}\text { Topo dt } \\
\text { Enesela }\end{array}$ & $\begin{array}{l}\text { Ww } \\
\text { Bw }\end{array}$ & $\begin{array}{l}210 \\
100\end{array}$ & $\begin{array}{l}7,3 \\
7.4\end{array}$ & $\begin{array}{l}1.63 \\
2,03\end{array}$ & $\begin{array}{l}6.79 \\
6,85\end{array}$ & $\begin{array}{c}\cdot \\
\text { n, } 74\end{array}$ & $\begin{array}{l}0,0 \\
1,12\end{array}$ & $\begin{array}{l}0,25 \\
0.24\end{array}$ & - & - & - \\
\hline Mela Encosta & $\begin{array}{l}\text { Ets } \\
\text { Gus }\end{array}$ & $\begin{array}{l}17 \\
160\end{array}$ & $\begin{array}{l}0,7 \\
7,2\end{array}$ & $\begin{array}{l}3,99 \\
2,05\end{array}$ & $\begin{array}{l}7,19 \\
6,35\end{array}$ & $\begin{array}{l}0,65 \\
0,74\end{array}$ & $\begin{array}{l}0,12 \\
0,12\end{array}$ & $\begin{array}{l}0,100 \\
0.35\end{array}$ & - & $=$ & - \\
\hline Sepede & A & 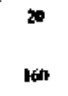 & $\begin{array}{l}7.4 \\
7.5\end{array}$ & $\begin{array}{l}3.69 \\
2.87\end{array}$ & $\begin{array}{l}4.91 \\
7.44\end{array}$ & $\begin{array}{l}0.60 \\
\$ .00\end{array}$ & $\begin{array}{l}0.23 \\
0.10\end{array}$ & $\begin{array}{l}0,33 \\
0.40\end{array}$ & . & + & . \\
\hline 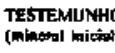 & & & $7 . x$ & 1,97 & 4,53 & 0.12 & 0,05 & 0.21 & 0,74 & 0,5 & ni, $\mathbf{x}$ \\
\hline
\end{tabular}

Tabela 2 - Resultados químicos das resinas sintéticas instaladas na região Amazônica

Table 2 - Chemical results of sintetic resins instated in the Amazonic region

\begin{tabular}{|c|c|c|c|c|c|c|c|c|}
\hline \multirow[t]{2}{*}{$\begin{array}{l}\text { LOCAL } \\
\text { AMOSIRADO }\end{array}$} & \multirow[t]{2}{*}{ HOH. } & \multirow[t]{2}{*}{$\begin{array}{l}\text { PROF. } \\
\text { (cm) }\end{array}$} & \multicolumn{6}{|c|}{ 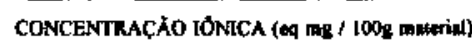 } \\
\hline & & & $\mathrm{Ca}^{2+}$ & $\mathrm{Mg}^{3+}$ & $K^{\prime}$ & $\mathrm{Al}^{3}$ & $\mathrm{Fe}^{\prime \prime}$ & $\mathrm{Mn}^{2}$ \\
\hline \multirow{2}{*}{$\begin{array}{l}\text { OPOO DE } \\
\text { ENCOSTA }\end{array}$} & Bt & 20 & 0,79 & 0,41 & 0,07 & 0,09 & 0.00 & 0,04 \\
\hline & $\mathbf{B w}$ & 140 & 0,47 & 0,42 & $0,0 \mathrm{~s}$ & 0,03 & 0,90 & 0,02 \\
\hline $\begin{array}{l}\text { MEIA } \\
\text { ENCOSTA }\end{array}$ & BtI & 17 & 1,66 & 1.47 & 002 & 0.03 & 0,00 & 0,02 \\
\hline $\begin{array}{l}\text { SOPÉ DE } \\
\text { ENCOSTA }\end{array}$ & 80 & 100 & 1.24 & 0,97 & 0,01 & 0.04 & 0,00 & 0,02 \\
\hline
\end{tabular}

sendo que na glicolação um pequeno deslocamento do pico de $1,47 \mathrm{~nm}$ (testemunho) para $1,42 \mathrm{~nm}$ nesse horizonte parece não ser significativo. No aquecimento a $350^{\circ} \mathrm{C}$, dois picos bem marcantes a $1,47 \mathrm{~nm}$ e $1,22 \mathrm{~nm}$ diferenciam-se do espaçamento a $1,26 \mathrm{~nm}$ do testemunho para esse tratamento. A $550^{\circ} \mathrm{C}$, apesar do espaçamento praticamente semelhante ao testemunho a 1,17 nm, é notado um pequeno pico diferenciador a $1,31 \mathrm{~nm}$.

COMPORTAMENTO QUÍMICO DO MINERAL-TESTE $\mathrm{Na}$ tabela 3 , mostram-se os resultados químicos dos minerais teste instalados na região Sul do Brasil; como na região Norte, essas "armadilhas" permaneceram por um ano no solo, sofrendo os efeitos de uma estação seca e uma estação chuvosa acumuladas. Os resultados obtidos para o testemunho (mineral inicial) são repetidos na parte inferior da tabela por conveniência na apresentação dos resultados.

É interessante destacar a diminuição, pela metade, da CTC para o mineral-teste instalado, a diminuição da concentração de magnésio adsorvido, também por um fator dois, e o aumento relativo da concentração de hidrogênio retido pela vermiculita, o qual, em média, dobrou para todos os solos da seqüência.

$\mathrm{O}$ cálcio tornou-se empobrecido nos sítios de troca dos minerais teste instalados nos horizontes B latossólico e B textural. O sódio, o potássio e o alumínio não mostraram variações marcantes em comparação com o mineral inicial, o mesmo acontecendo com o pH em água.

Para as resinas catiônicas instaladas na região Sul e analisadas após extracão com HC1 0,05 $\mathrm{N}$ (para $\mathrm{Ca}^{2+}, \mathrm{Mg}^{2+}$ e $\mathrm{K}^{+}$) e $\mathrm{KCl}\left(\mathrm{H}^{+}\right.$e $\left.\mathrm{Al}^{3+}\right)$ os resultados estão na tabela 4 . 
Para os solos da seqüência da região Sul, é observada maior "circulação" de hidrogênio, o qual é mobilizado ao longo de toda a cobertura pedológica. É destacada a mobilização relativamente alta de potássio no horizonte $\mathrm{Al}$ da encosta, assim como de magnésio no horizonte B textural.

DINÂMICA PEDOLÓGICA DA REGIÃO SUL O uso dos métodos do mineral-teste e da resina catiônica mostrou características gerais do funcionamento atual do sistema pedológico da região Sul.

Os resultados químicos obtidos com a resina, considerados como uma amostra da solução do solo (Binkley\& Hart 1985), revelou principalmente uma mobilização de hidrogênio, o qual "circula" mais no volume latossólico e em seguida na camada B textural. Isso está coerente com os ambientes intempéricos desses materiais, descritos por Birkeland (1974) e Andrade et al. (1976).

O comportamento químico e mineralógjco dos mineraisteste instalados no sul mostrou-se complexo, tendo sido possível fazer considerações sobre as tendências de funcionamento atual do sistema daquela região.

Pela química, foi observado abaixamento da CTC dos minerais-teste instalados, tendo os sítios de troca permanecido predominantemente preenchidos por magnésio.

Foi notada tendência de enriquecimento superficial do sistema em cálcio, devido provavelmente à ciclagem biológica (Golley et al. 1978).

Tabela 3 - Resultados químicos dos minerais-teste instalados na região $\mathrm{Sul}$

Table 3 - Chemical results of the test minerals instated in the South region

\begin{tabular}{|c|c|c|c|c|c|c|c|c|c|c|}
\hline \multirow[t]{2}{*}{$\begin{array}{l}\text { LOCAL } \\
\text { ANOSTRADO }\end{array}$} & \multirow[t]{2}{*}{ HON. } & \multirow{2}{*}{$\begin{array}{l}\text { PROF. } \\
\text { INSTAL. } \\
\text { (ani) }\end{array}$} & \multirow[t]{2}{*}{ pat } & \multicolumn{7}{|c|}{ 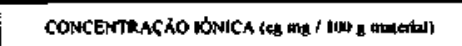 } \\
\hline & & & & con. & M\&: & Nan. & x. & $\mathbf{H}$ & Al. & CTC \\
\hline $\begin{array}{l}\text { oro de } \\
\text { Neosta }\end{array}$ & $\begin{array}{l}\text { A } \\
\text { B* }\end{array}$ & 100 & $\begin{array}{l}7.2 \\
7.1\end{array}$ & $\begin{array}{l}11 .+3 \\
\\
41,97\end{array}$ & $\left\{\begin{array}{l}21.14 \\
25,67\end{array}\right.$ & $\begin{array}{l}0.14 \\
0.10 \\
0.11\end{array}$ & $\begin{array}{l}\text { u, on } \\
\text { an, }\end{array}$ & $\mid \begin{array}{l}0,11 \\
0.57\end{array}$ & $\begin{array}{l}4,02 \\
4.1 .15\end{array}$ & $\begin{array}{l}2.27 \\
30,19\end{array}$ \\
\hline & At & 10 & T. & .29 & $2+.51$ & 11,13 & $0,+5$ & 0.42 & 1..112 & 3.82 \\
\hline
\end{tabular}

Tabela 4 - Resultados químicos das resinas sintéticas instaladas na região Sul

Table 4 - Chemical results of the sintetic resins instated in the South region

\begin{tabular}{|c|c|c|c|c|c|c|c|c|}
\hline \multirow[t]{2}{*}{$\begin{array}{l}\text { LOCAL } \\
\text { AMOSTRAD }\end{array}$} & \multirow{2}{*}{ 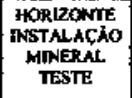 } & \multirow{2}{*}{$\begin{array}{l}\text { PROFUNDIDADE } \\
\text { DE INSTALACAO } \\
\text { (am) }\end{array}$} & \multicolumn{6}{|c|}{ 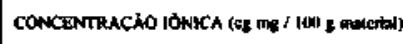 } \\
\hline & & & $\omega^{*+}$ & $4 e^{2+1}$ & $\mathbf{k}^{\prime}$ & H' & $\mathrm{Al}^{31}$ & $\operatorname{CTC}$ \\
\hline $\begin{array}{l}\text { TOPO DE } \\
\text { ENCOSTA }\end{array}$ & BW & Ifil & 0.00 & 1.,601 & 0.30 & 2.13 & 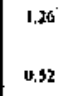 & 4.16 \\
\hline $\begin{array}{l}\text { MEE|A } \\
\text { EMCOSTA }\end{array}$ & & & $\begin{array}{l}0.11 \\
0.07\end{array}$ & 1,21 & $\begin{array}{l}2115 \\
\text { 1.1. } 1.8\end{array}$ & 11, nh & 0.20 & 1.74 \\
\hline
\end{tabular}

As modificações estruturais sofridas pelos minerais-teste instalados foram complexas; tentou-se separá-las em dois padrões distintos: 1. as que ocorreram no volume representado pelo horizonte B textural, e 2. as que se manifestaram no volume latossólico e no horizonte superficial da meia encosta.

No primeiro caso, é possível dizer que houve manutenção das características de espaçamento da vermiculita-testemunho saturada com $\mathrm{K}^{+}$a $25^{\circ} \mathrm{C}$; a diferença recai nos aquecimentos, mesmo a $350^{\circ} \mathrm{C}$ o mineral amostrado não "fechou" suas lâminas, isso aconteceu parcialmente a $550^{\circ} \mathrm{C}$ para o horizonte $\mathrm{Bt}$. Tal fato pode estar ligado a algum tipo de bloqueio interfoliar dessa vermiculita.

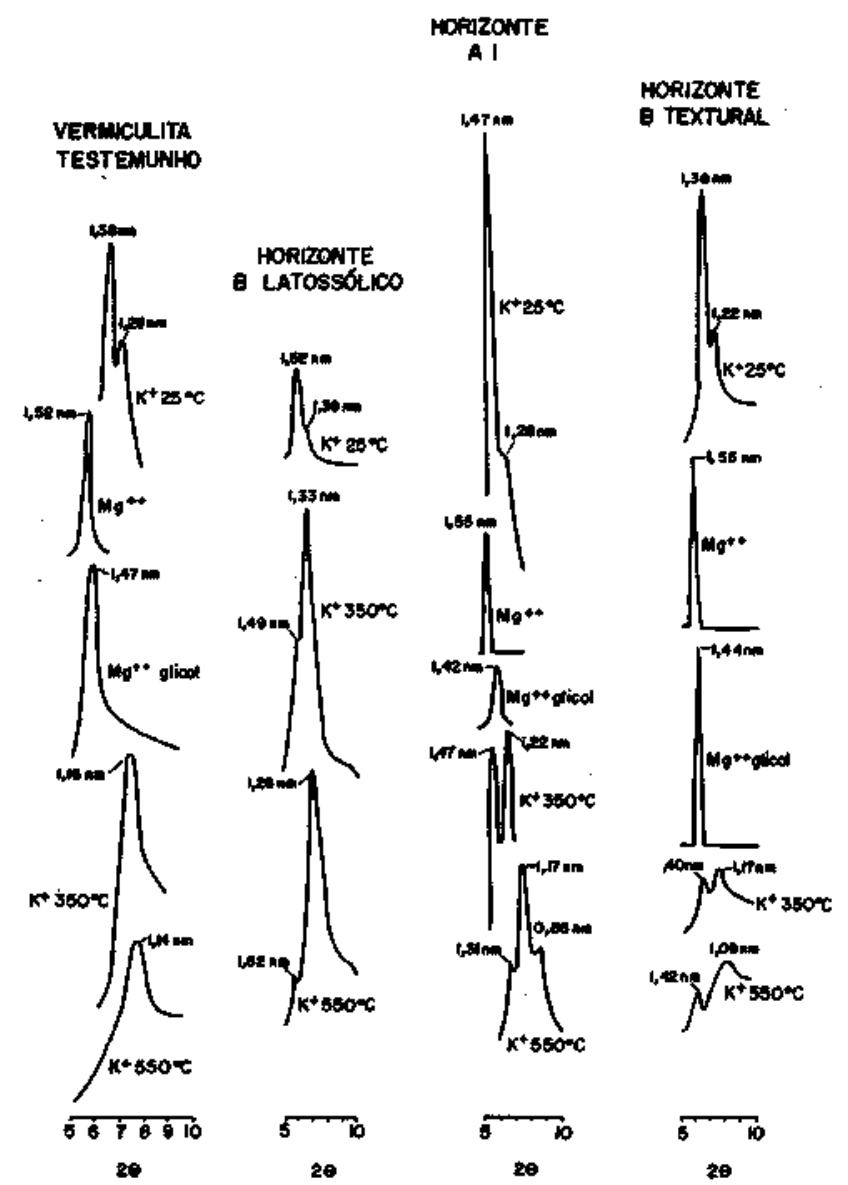

Figura 5 - Modificações estruturais do mineral-teste após permanência de um ano na cobertura pedológica da região Sul

Figure 5 - Structural modifications of the test mineral after permanence of one year in the pedological cover of the South region

O segundo grupo de mudanças estruturais, com base principalmente na saturação com $\mathrm{K}^{+} \mathrm{a} 25^{\circ} \mathrm{C}$, foi considerado como uma "montmorillonitização" da vermiculita, devido ao aparecimento de um pico marcante a $1,5 \mathrm{~nm}$, relacionado à montmorillonita (Besoain 1985). Essa "montmorillonita", mesmo quando aquecida a $550^{\circ} \mathrm{C}$, mostrou-se altamente bloqueada. As amostras do volume latossólico e do horizonte A 1 da meia encosta deslocaram-se respectivamente para 1,3 $\mathrm{nm}$ e $1,2 \mathrm{~nm}$, espaçamentos indicativos, conforme Barnhisel (1982), de uma alto grau de preenchimento interfoliar por algum agente bloqueante, o que pode explicar a diminuição da CTC observada nos minerais instalados na região Sul.

AMBIENTE GEOQUÍMICO ATUAL DA REGIÃO SUL Finalmente, é possível dizer que o meio ácido atestado pela mobilização de hidrogênio na solução do solo, aliada à acentuação dos mecanismos de bloqueio interfoliar, sugerem uma dinâmica geoquímica caracterizada por acidólise simples (Felix 1987), o que pode indicar uma tendência à acidifícação crescente para o sistema pedológico do sul do país.

CONCLUSÃO A utilização dos métodos experimentais dos minerais-teste e da resina trocadora de íons, aplicados a coberturas pedológicas desenvolvidas sobre rochas básicas situadas nas regiões Amazônica e Sul do Brasil, permitiu caracterizar a dinâmica geoquímica atual daquelas coberturas. Conclui-se que, para a região Norte, atualmente atuam mecanismos de podzolização do sistema pedológico, enten- 
dendo-se por isso uma tendência intempérica ácidocomplexante na evolução pedológica daquela área. Na região Sul, está ocorrendo "acidifícação" do sistema, ou seja, uma tendência à acentuação de um intemperismo tipo latossólico, mais agressivo e lixiviante.
Agradecimentos Os autores agradecem a colaboração dó Institui National de la Recherche Agronomique (INRA), Ministério de Relações Exteriores da França e ORSTOM, sem a qual não seria possível a realização deste trabalho.

\section{REFERÊNCIAS BIBLIOGRÁFICAS}

ANDRADE S S ; MONIZ A.C · SANTOS, H.G · ALMEIDA, H.C. 1976. Seqüência de evolução de solos bem drenados originados de rochas eruptivas básicas da região físiográfica de Campo Grande, MT. In: CONGR. BRÁS. CIÊNCIA DO SOLO, 15. Campinas, 1976. Anais... Campinas, SBCS.

BARNH1SEL,R.1.1982.Chlorites and hidroxyinterlayeredvermiculiteand smectite. In: DIXON, J.B. \& WEED, S.B. ed. Minerals in Soil Environments. Madison, Soil Science Society of America, p. 331 - 350.

BERTHELIN, J. SADIO, S · GUILLET, B * ROULLIER, J. 1983. Alteration experimentale de mineraux argileuxdiettrioctaedriques dans un podzolet dans unsol brun acide.Sc/. Géôl. Mém, 71:13-23.

BESOAIN, E. 1985. MineralogíadeArcillasdeSuelos. Costa Rica, Instituto Interamericano de Cooperacion para Ia Agricultura. $1205 \mathrm{p}$

BINKLEY,D \& HART, S.C. 1985. Correlations among indices of forest soil nutrient availability in fertilized and unfertilized loblolly pine plantations. Plant and Soil 85:11-21.

BINKLEY, D. \& MATSON, P. 1983. Ion exchange resin bag method for assessing forest soil nitrogenavailability.Soi'/Sc. Soc. Am J.41(5): 1050-1052.

BIRKELAND, P.W. 1914.Pedology, Weathering and Geomorphological Research. New York, Oxford University Press. 285 p.

DEPARTAMENTO NACIONAL DA PRODUÇÃ̃O MINERAL 1974 Projeto RADAM. Folha Belém. Rio de Janeiro, Ministério das Minas e Energia. (Levantamento de Recursos Naturais, 5).

DEPARTAMENTO NACIONAL DA PRODUCÃO MINERAL 1978. Carta Geológica do Brasil ao Milionésimo. Folha Paranapanema. Brasília, Ministério das Minase Energia.

FELIX, C. 1987. Etude du Fonctionnement Geochimique Compare dês Sois Acides - Utilisation dês Vermiculites Test in Situ pour L 'Etude du
Fonctionnement Saisonier et Actuelde PodzolsetsolsBruns. Nancy. 82 p. (D.E.A., Université Nancy I).

GOLLEY,F.B.;McGINNIS,J.T.;CLEMENTS,R.G.;CHILD,G.I.;DUEVER, M.J. 1978. Ciclagem de Minerais em um Ecossistema de Floresta Tropical Úmida. São Paulo, EPU/EDUSP. 256 p.

HATTON, A.; RANGER, J.; ROBERT, M.; NYS, C.; BONNAUD, P. 1987. Weathering of a mica introduced into four acidic forest soils. J. SoilSci. 38(2): 179-190.

LEMOS, R.C. \& SANTOS, R.D. 1984. Manualde Descriçãoe Coletade Solo no Campo. Campinas, SBCS/SNLCS. 46 p.

MEHRA, O.P. \& JACKSON, M.L. 1960. Iron oxide removal from soils and clays by a dithionite citrate system buffered with sodium bicarbonate. Clays and Clay Minerals, 7:317-327.

RANGER, J. \& ROBERT, M. 1985. Caractérisation du fonctionnement physico-chimique des sols forestiers par une approche experimentale utilisant 1' evolution de mineraux primaires. Agronomie, 5(2): 157-168.

ROBERT, M; RAZZAGHI, M.K.; VICENTE, MA.; VENEAU, G. 1979. Role du facteur biochimique dans 1 'alteration des mineraux sit reates. Sei. Sol., (2/3): 153-174.

ROCHA, G.C. 1990. Características e Dinâmica deCoberturasPedológicas sobre Rochas Básicas nas Regiões Norte e Sul do Brasil. São Paulo. 246 p. (Tese de Doutoramento, ESALQ/USP).

MANUSCRITOA681

Recebido em 13 de novembro de 1990

Revisão do autor em 29 de janeiro de 1992 Revisão aceita em 3 de fevereiro de 1992 